\title{
DESCARTES Y HOBBES
}

Francesc Arroyo

Da hasta vergüenza decir según que cosas. Sin embargo, de vez en cuando hay que decirlas, no basta con pensarlas. Permitanme ahora enunciar uno de esos hechos que son ciertos: El mundo existe. Es eso que está entre ustedes y yo y nos incluye.

Heclıa esta declaración de principios, no perderé un ápice de tiempo (lo único que tenemos y que tan rápido se va) (ratando de demostrarlo. Entre otras cosas porque ya lo laan hecho por mi Hobbes y Descartes, quienes discreparon mucho, pero en este ámbito de la ontologia tenian un acuerdo bastante general.

Otro asunto es que ambos llegaran a la misma convicción por caminos y vias diferentes, pero to importante no siempre es el camino, a veces puede resultar más interesante la meta.

Lo cierto es que, en el verano de 1648, el marqués de Newcasıle consiguió reunir en una misma mesa a Hobbes y Descartes. Fue en ocasión de una comida a la que también asistió Pierre Gassendi, asi como el poeta y admirador de Hobbes Edmund Waller. Los dos pensadores aprovecharon ese encuentro para mantener una larga cliarla sobre la dureza, inexplicable, con la que habian hecho públicas sus discrepancias.

Las relaciones entre Hobbes y Descartes fueron, en términos generales, insoportables. F. Brandt ha llegado a afirmar que la principal fuente de discrepancias entre ambos tra, precisamente, su coincidencia en no pocos puntos. Pasaré por alto una supuesta competencia entre ambos sobre la autoria prioritaria de determinada afirmaciones sobre, por cjemplo, el color o el movimiento.

Muy posiblemente, como en el caso de la polémica sobre el cálculo infinitesimal entre Newton y Leibniz, la coincidencia no sea tanto producto del plagio como de la capacidad del espíritu del tiempo para influir en individuos concretos.

El vínculo entre ambos pensadores, vuelvo a referirme a Descartes y Hobbes, lue, desde luego, el abate Merssenne, a quien conoció llobbes durante una de sus estancias en el continente y a quien frecuentó especialmente durante el período de 1610 a 1651 , cuando vivió en Paris.

Descartes y Hobbes se encontraron una sola vez, la que ya he relatado y que la narrado Waller y han recogido la mayoria de biógralos de Hobbes, entre cllos, J. Aubrey. Fue ese encuen. tro la última vez que Descartes estuvo en la capital de Francin, poco antes de instalarse en Suecia.

Previamente, en 1645, hubicran podido coincidir también. pero Hobbes evitó deliberadamente el encuentro. $Y$ es que, verdaderamente, se profesaban escaso carino, aunque se tuviera consideración intelectual.

La correspondencin de ambos muestra de forma clara y distinta la ambivalencia de los juicios reciprocos. Pondremos sólo unos pocos ejemplos.

En 1646, Hobbes escribe a Sorbière, que más tarde traduciria el De Cive, con ınotivo de la próxima aparición de este mismo texto:

Si el seitor Descartes llegara a notar o sospechar los preparativos para la publicación de ini obra, estoy seguro de que maniobrará lo que pueda, crbannelo usted, porque lo sé.

Tres anos antes, en 16+3, habia sido Descartes quien, en una carta a un destinatario desconocido, escribio: 
Encuentro (a Hobbes) mucho más hábil en moral que en metarisica o en fisica, si bien no puedo aprobar sus principios y míximas, muy peligrosis, en cunnto que suponen que todos los hombres son malvados o tienen motivos para serlo.

A este juicio de valor, lo conociera o simplemente lo intuyera, responde Hobbes reconociendo a Descartes mérito como geómetra y añadiendo que hubiera dado buenos frutos de haber persistido en ello, en lugar de adentrarse en la filosofía con tan pobres resultados, stugún recoge Aubrey, que añade una coletilla que pone el dedo en la llaga. A saber, que lo que verdaderamente no podia digerir Hobbes de Descartes era su teología.

En efecto. La clave está en la discrepancia teológica y aủn teologal. Y es que, como no podia ser menos tratándose de grandes pensadores, ambos vieron pronto qué pie calzaba el rival.

Quien esté especialmente interesado en la polénica filosófica encontrará el núcleo de la misma en las objeciones de Hobbes a las Meditaciones Metafisicas de Descartes, y en las respuestas de éste.

De esta obra hay una traducción adecuada en los Clásicos de Alfaguara, hecha por Vidal Peria, a la que no quiero yo dejar de hacer, aunque menor, una objeción.

Antes, sin embargo, voy a referirme someramente a este tipo de acción, la discrepancia critica.

En mi opinión, una cultura sin polémica es una cultura mortecina. La discusión, la discrepancia y su expresión pública son sintomas de vitalidad cultural y de respeto por el adversario. No nos engaìemos, discutir con alguien es reconocer que nos lo tomamos en serio y pensar que vale la pena plantarle cara. blando.

El elogio sistemático y el silencio, en ambos casos, son inaceptables, filosóficamente la-

El primero es, en el fondo y en la superficie, un insulto solapado. Sólo de los tontos esperamos que crean que su corbata es la más bonita del mundo y que su modo de pensar carece de precedentes y no tendrá igual en el futuro.

El silencio es el abandono de la palabra, el rechazo de aquello que nos caracteriza como humanos.

Añadiré que hoy vivimos, en el ámbito de la cultura, tiempos de silencios y elogios desmedidos, apenas roto por quienes pretenden que la critica es la descalificación y el insulto del contrario convertido en enemigo. Tiempos en los que releer las Meditaciones, con objeciones $y$ respuestas, produce un escozor casi de envidia.

Y no quiero dejar de preguntarme cuảntos pensadores contemporáneos admitirian pasar un original a la critica de sus colegas y se tomarian luego el trabajo de responderles.

No tengo respuesta. La imagino, pero no la formulo en voz alta porque, como Descartes, temo estar engañado por un potente genio maligno.

Tras este breve paréntesis, la objeción de Vidal Peña, a quien desde hace tiempo admiro. En castellano, las ordinales posteriores a décima no son onceava, doceava, etcétera. Asi pues, Hobbes, el filósofo inglés de las tercera objeciones, dicho sea de paso para aquéllos que no lo hubieran identificado, formula 16 objeciones a Descartes. La última de ellas está bien adjetivada en la traducción de Peña, pues se la ha llamado precisamente "última". No asi la undécima, duodécima, décimo tercera, décimo cuara y décimo quinta, denominadas, respectivamente, onceava, doceava, treceava, catorceava y quinceava, términos cuyos sentido es otro.

Y no será vano citar aqui parte de la respuesta octava, aqui si la terminación es correcta, sobre la conveniencia de ponerse de acuerdo respecto al sentido de las palabras, aunque sólo 
sea porque en los últimos tiempos está mal visto hablar de filosofia sin hacer alguna referencia, por banal que sea (y lo son tantas) al lenguaje.

Volvamos ahora, brevemente porque el tiempo corre, a los puntos flacos de Hobbes y Descartes, es decir a la teologia.

Hobbes, por más que lo intentó, no engañó a nadie. En todas sus obras colocaba abundantes páginas demostrando que lo que él decia iba a misa, es decir, casaba con las airmaciones biblicas. Y tanto esfuerzo sólo sirvió para que, poco después de morir él, los estudiantes ingleses, en un gesto de insólita civilización, quemaran sus escritos por ateos.

De ahi que el hecho de que Descartes constituyera a Dios en garante del conocimiento le estomagara, como dice Aubrey. Buena parte de sus objeciones son circunloquios de una y la misma afirmación: Dios existe, por favor, señor Descartes, búsquese otro apoyo, que lo hay. Pero nunca lo escribió con esta claridad.

Descartes, claro, lo entendió perfectamente y se negó a cambiar. Habria que ver si el Dios cartesiano tiene existencia real o, como ocurre con el de Hobbes, da lo mismo, porque aunque no existiera todo seguiria igual. Ésta, desde luego, es mi opinión. En la medida en que es la razón la que crea a Dios, es la razón la última garante del conocimiento.

Dios, desde luego, no es la piedra filosofal. Dicho lo cual, permitanme cerrar esta exposición recordando que Hobbes, con 91 anoos, próximo a la muerte, escribió para su lápida una inscripción que nunca seria grabada:

"Esta es la verdadera piedra filosofal"

Hacia ella vamos. 